\title{
An Immunoproteomic Survey of the Antibody Landscape: Insights and Opportunities Revealed by Serological Repertoire Profiling
}

\author{
Steven Ionov and Jiwon Lee* \\ Thayer School of Engineering, Dartmouth College, Hanover, NH, United States
}

OPEN ACCESS

Edited by:

Yariv Wine,

Tel Aviv University, Israel

Reviewed by:

Victor Greiff,

University of Oslo, Norway

Christoph M. Hammers,

University of Lübeck, Germany

${ }^{*}$ Correspondence:

Jiwon Lee

jiwon.lee@dartmouth.edu

Specialty section: This article was submitted to Systems Immunology, a section of the journal

Frontiers in Immunology

Received: 09 December 2021

Accepted: 14 January 2022

Published: 01 February 2022

Citation:

lonov S and Lee J (2022) An Immunoproteomic Survey of the

Antibody Landscape: Insights and Opportunities Revealed by Serological Repertoire Profiling.

Front. Immunol. 13:832533. doi: 10.3389/fimmu.2022.832533
Immunoproteomics has emerged as a versatile tool for analyzing the antibody repertoire in various disease contexts. Until recently, characterization of antibody molecules in biological fluids was limited to bulk serology, which identifies clinically relevant features of polyclonal antibody responses. The past decade, however, has seen the rise of massspectrometry-enabled proteomics methods that have allowed profiling of the antibody response at the molecular level, with the disease-specific serological repertoire elucidated in unprecedented detail. In this review, we present an up-to-date survey of insights into the disease-specific immunological repertoire by examining how quantitative proteomicsbased approaches have shed light on the humoral immune response to infection and vaccination in pathogenic illnesses, the molecular basis of autoimmune disease, and the tumor-specific repertoire in cancer. We address limitations of this technology with a focus on emerging potential solutions and discuss the promise of high-resolution immunoproteomics in therapeutic discovery and novel vaccine design.

Keywords: Ig-Seq, serological antibody repertoire, proteomics, infectious disease, cancer, autoimmunity

\section{INTRODUCTION}

The discovery of a substance in serum with the ability to protect against disease dates back to Emil von Behring and Shibasaburo Kitasato (1); just a year later, Paul Ehrlich made the first reference to 'Antikörper', or antibodies, in an 1891 report (2). No less important in retrospect was Karl Landsteiner's discovery 50 years later that antisera contain specificities to multiple antigens (3); this may be viewed as the discovery of an antibody repertoire. The serological repertoire is comprised of a diverse combination of immunoglobulins secreted by $\mathrm{B}$ cells in various compartments including peripheral blood, bone marrow, and mucosal sites $(4,5)$. From initial exposures to exogenous and endogenous (in the case of cancer and autoimmune disease) antigens, the antibody repertoire is established and constantly reshaped through subsequent exposures to a multitude of different antigens during one's lifetime $(6,7)$.

Characterization of serum antibodies has traditionally relied on serological assays that determine the total abundance, binding specificity, and neutralizing activity of polyclonal antibodies using various techniques, including enzyme-linked immunosorbent assays (ELISA) as well as neutralization and immunofluorescence assays $(8,9)$. Though serology remains essential in the 
present-day study of antibody responses (10) and gives critical insights into the global immune repertoire, it does not inform on the traits of individual constituent antibody molecules. More recently, single B cell sequencing has allowed recombinant expression and characterization of monoclonal antibodies (mAbs), leading to functional delineation of antibody responses at the single-mAb level and discovery of numerous $\mathrm{mAbs}$ with potent therapeutic activity (11). However, as some B cells do not secrete antibodies, B-cell-based studies are often unable to accurately determine the relative abundance of each identified $\mathrm{mAb}$, or its relevance to serological protection. As protective antibody molecules that circulate in blood or coat mucosal surfaces are the key correlate of humoral immunity to various diseases (12), proteomic studies of abundant immunoglobulins are critical to in-depth analysis of the antibody landscape.

Over the last two decades, mass spectrometry (MS) has found increasing use in the analysis of complex protein samples (13); more recently, it has been applied to profiling of polyclonal antibody mixtures, giving rise to next-generation serology (1417). The proteomic deconvolution of antigen-specific serum antibody mixtures, pioneered by the Georgiou group, is known as Ig-Seq $(14,15,18)$ (Figure 1). This method has allowed identification, quantification, and longitudinal tracking of antibody lineages at the molecular level. Ig-Seq is a bottom-up proteomic approach involving affinity purification of antibodies against a target antigen, followed by analysis via a liquidchromatography-tandem-MS (LC-MS/MS) system. Generated peptide spectra are then matched to a sequence database (19), often constructed by high-throughput B cell sequencing [BCRSeq, reviewed in (20-22)] to identify serum antibodies and enable their subsequent recombinant expression as mAbs for further functional study (15, 23-25). Technical advances and challenges in mass-spectrometry based antibody sequencing, from sample preparation to computational pipelines, have been recently reviewed comprehensively by Greiff and colleagues (26). In this mini review, we present a survey of the various pathologies explored to date using antibody mass spectrometry, highlighting unique insights into the characteristics of the diseasespecific immune repertoire and the therapeutic molecules or strategies which may arise from these studies. We emphasize the implications of disease-specific insights in combating infectious disease, autoimmunity, and cancer.

\section{APPLICATIONS OF IG-SEQ TO STUDY DISEASE}

\section{Infectious Disease Influenza}

In 1947, a seminal study observed that university students infected with influenza, who had been previously vaccinated against a different influenza strain, had higher serum antibody titers against the original vaccine strain than the infecting strain (27); this serologic phenomenon was later described by the authors as 'original antigenic sin' (28). Numerous studies have since demonstrated that the antibody repertoire generated from early exposure to influenza is 'imprinted' on the immune system. This set of antibodies persists in circulation and exerts a major influence on the nature of the antibody response upon subsequent exposure (27, 29-33). Despite mounting evidence of immune imprinting in the context of influenza, precise understanding of how these pre-existing antibodies can
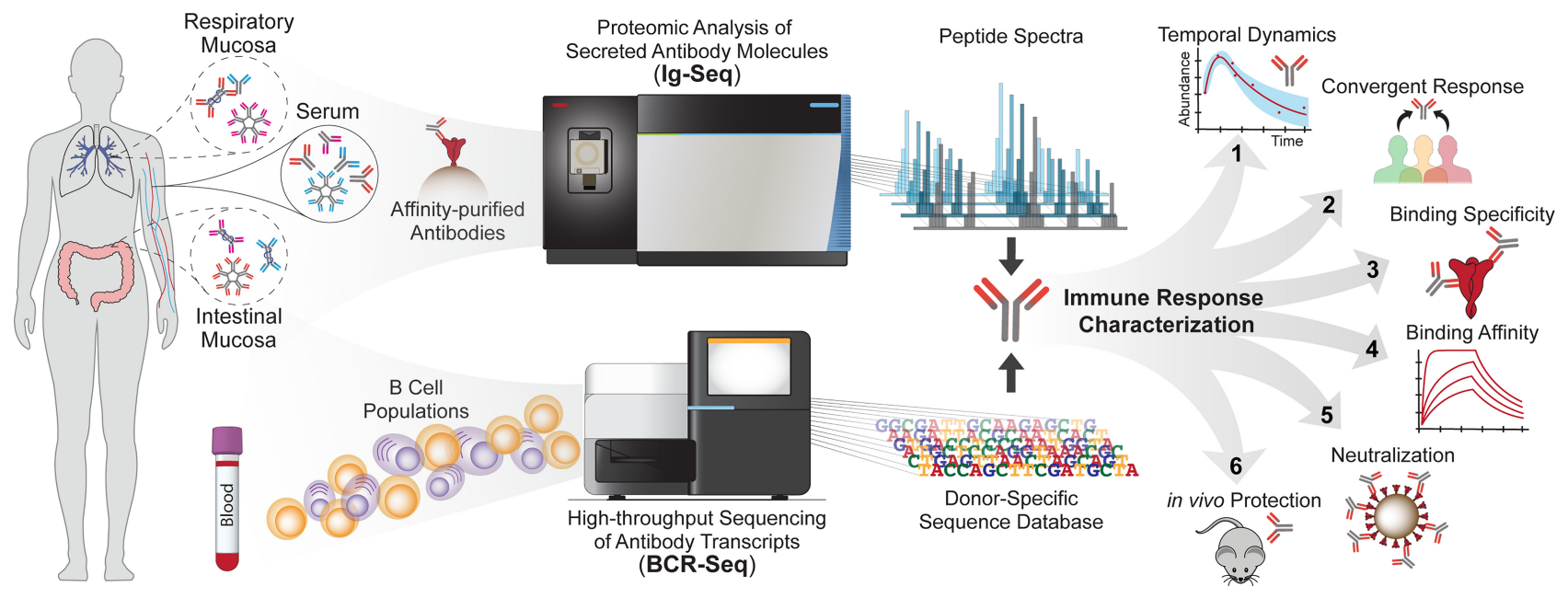

FIGURE 1 | Quantitative and qualitative profiling of antibody repertoires using the Ig-Seq pipeline. Antibodies sampled from biological fluids are subject to affinity purification against an antigen of interest and profiled by mass spectrometry (top pathway). A donor-specific reference database generated from BCR-Seq (bottom pathway) is used to match peptide spectra with antibody sequences. Relative antibody abundances are profiled in detail and can be tracked longitudinally. Ig-Seq enables detailed longitudinal profiling of antibody repertoires (1), identification of convergent responses (2), functional characterization of antibody specificity (3) and affinity (4), as well as delineation of the in vitro neutralization (5) and in vivo protection (6) conferred by abundant antibodies. Insights from the repertoire's behavior after antigenic exposure, and the protective features of expressed mAbs, inform the design of diagnostics, vaccination strategies, and therapeutics. 
influence the elicitation of new antibodies has been impeded by the inability to identify pre-existing antibodies using bulk serological assays. Lee et al. addressed this gap by using Ig-Seq to quantitatively interrogate the serological repertoire of young adults before and after seasonal influenza vaccination to differentiate between pre-existing (i.e., already present in circulation before the vaccination) and de novo (i.e., newly elicited following the vaccination) repertoires (34). The authors showed that $>60 \%$ of the post-vaccination hemagglutinin (HA)specific repertoire consisted of pre-existing antibodies which tended to be cross-reactive to $\mathrm{H} 1$ and $\mathrm{H} 3$ subtypes while de novo antibodies were mostly specific to one subtype, suggesting that the pre-existing population targeted conserved regions on HA. Recombinant expression of representative cross-reactive antibodies revealed a conserved, previously uncharacterized epitope present at the 'interface' of trimeric HA. These antibodies conferred prophylactic and therapeutic protection in mice against divergent influenza strains. Other groups have since confirmed the protective ability and prevalence of HA interfacetargeting antibodies (35-38).

A subsequent study investigated the longitudinal dynamics of the HA-reactive antibody repertoire in an individual across 5 years of repeated exposure to the same H1N1 (A/California/4/ 2009; CA09) strain (39). With Ig-Seq enabling the identification and quantification of influenza-specific serum antibodies at multiple timepoints, the authors showed that a small group of 'persistent' antibodies circulating in serum across five years made up $\sim 70 \%$ of the CA09-reactive serum titer, demonstrating the remarkable stability of serological antibody repertoires. In other words, each vaccination elicited new antibodies making up 30\% of the anti-HA titer, but these 'transient' antibodies decayed away while the 'imprinted' repertoire remained. The persistent antibodies were more mutated and displayed more crossreactivity to a divergent $\mathrm{H} 5 \mathrm{~N} 1$ influenza strain compared to non-persistent antibodies.

Most of the population is exposed to influenza at an early age, whether due to infection by the circulating virus or through childhood vaccines (40). Older adults are likely to have been exposed on many occasions to both viral and vaccine antigens. The ability to elicit de novo protective immune responses decreases with old age (41), accentuating the importance of a broadly protective persistent repertoire. This impact of age on the influenza-reactive antibody repertoire has been investigated by determining the relative abundances of antibodies crossreactive to $\mathrm{H} 1$ and $\mathrm{H} 3$ across adults aged 26-70 before and after seasonal vaccination (42). The study revealed that older individuals (suggesting increased exposure events) had a larger relative abundance of cross-reactive antibodies, with over $90 \%$ of the vaccine-specific repertoire in some elderly donors displaying reactivity to both $\mathrm{H} 1$ and $\mathrm{H} 3$. Strikingly, subsequent in-depth characterization of broadly cross-reactive serum antibodies revealed that they recognized sulfated glycans abundant in avian egg-prepared vaccines, likely rendering them ineffective in preventing infection. Collectively, the quantitative nature of Ig-Seq and the ability to track antibodies longitudinally enabled studies focusing on the molecular and functional features of imprinted influenza serum antibody repertoires.

\section{SARS-CoV-2}

The onset of the COVID-19 pandemic raised the urgency to understand the immune response to viral infection, and more recently, vaccination. Serological studies of SARS-CoV-2infected patients and analysis of their B cells led to rapid profiling of longitudinal antibody responses to infection (43$46)$, contributing to the unprecedented speed of new and effective vaccine development (47) and discovery of neutralizing mAbs (48-53). While these data have improved our understanding of protection afforded by serum antibodies, the relative abundance and functionalities of the individual SARS-CoV-2-reactive antibodies circulating in blood have remained unknown. The traits of individual antibodies are clinically important based on previous serological repertoire analyses, which indicate a high degree of polarization [i.e., a small number of antibodies comprising a large fraction of the overall response $(14,15,34$, $39,42,54)]$. To address this, Ippolito and colleagues profiled the SARS-CoV-2 Spike (S) protein-reactive serological repertoire in COVID-19 patients during early convalescence (55). They determined that over $80 \%$ of S-specific IgG in sera bound to regions other than the receptor-binding domain (RBD), a primary target of neutralizing antibodies. Instead, many highly abundant antibodies (some of which individually comprised $>20 \%$ of the S-specific repertoire) bound to the N-terminal domain (NTD), and functional characterization of those NTDbinding $\mathrm{mAbs}$ showed robust neutralization activity $\left(\mathrm{IC}_{50}\right.$ as low as $10 \mathrm{ng} / \mathrm{mL}$ ). However, NTD binding decreased or was completely ablated when the authors introduced mutations present in SARS-CoV-2 variants of concern (56). Thus, a sizable portion of antibodies were demonstrably susceptible to mutations in their binding epitopes, implying that their protective ability was not robust against emerging mutants.

Given that anti-S IgG binding titers are thought to be wellcorrelated with protection against SARS-CoV-2 infection (10), a recent study sought to determine the longitudinal dynamics of individual S-reactive serum antibodies over four months in convalescent patients (57). The authors specifically tracked peptides containing the complementarity determining region of heavy chain 3 (CDR-H3) using multiple reaction monitoring (MRM) (58), which enables precise quantitation of pre-selected peptides within a complex mixture. The authors built a model simulating the decay of S-specific serum antibodies and determined that antibody levels drop below a chosen seroconversion threshold of 1:40 around 70 days after onset of symptoms. This finding is in agreement with the observation of short-lived nature of antibody responses following SARS-CoV-2 infections (59), although the thresholds for protection are as yet uncertain. This work further highlights the urgency to better understand the longevity of SARS-CoV-2-specific antibodies in secretions, which may present important implications for developing vaccines capable of eliciting durable antibody responses.

\section{Other Infectious Disease}

The therapeutic impact of broadly-neutralizing antibodies (bnAbs) has been demonstrated in infectious disease (60), suggesting that the antibody repertoire can be an expansive 
reservoir for mining potent therapeutic candidates against microbial pathogens. Lindesmith et al. longitudinally profiled patients before and after vaccination against norovirus (HuNoV) (54), and found a pre-existing antibody, A1431, that was boosted 126 -fold by vaccination. A1431 bound to conserved viral capsid epitopes and neutralized a broad panel of $\mathrm{HuNoV}$ strains, including strains first observed years after the patient was vaccinated. The sera of patients with chronic infections such as HIV have also been studied with similar methods, as chronic stimulation of B cells by viruses that undergo immune escape may give rise to bnAbs (61). For example, one study functionally characterized abundant antibodies against the HIV Env glycoprotein MPER region in a chronically infected donor (62). The authors swapped the chains of several bnAbs found using Ig-Seq to generate a chimeric mAb that neutralized 206/ 208 global isolates of HIV-1. Similar work has been done to analyze antibodies identified in sera collected from 2 HIV eliteneutralizers (63), finding one in particular, N49P7, which was able to neutralize $117 / 117$ pseudoviruses of a global panel due to its ability to bind conserved inner-layer residues of the gp120 glycoprotein (64). Additionally, Ig-Seq-based repertoire profiling has been similarly applied in malaria (65) and hepatitis C (66), leading to the isolation and delineation of mAbs with protective qualities.

\section{Autoimmune Disease}

While the secreted antibody repertoire may act as the principal protective force in infectious disease immunity, the same repertoire acts as a primary agent of pathogenesis in autoimmune conditions (67-69). To this end, groups have applied Ig-Seq to study serologic signatures of systemic lupus erythematosus (SLE), namely anti-dsDNA antibodies and antibodies expressing the 9G4 idiotype ('9G4 antibodies') (70, 71). One study sequenced anti-dsDNA antibodies from SLE patients and found a preference for mutations to arginine in antibody variable regions, consistent with observations from previous $B$ cell sequencing studies that these mutations enable DNA binding (71). Others have compared spectra of purified 9G4 antibodies with sequences of donor-matched antibodysecreting cells (ASC's), which expand rapidly during SLEassociated disease 'flares' (70). The sequences from ASC's matched peptide spectra exactly, indicating that these ASC's, which were derived from naïve B cells, had a profound impact on the SLE serological repertoire. In the case of celiac disease patients, a more recent study found a gene preference for IGHV5-51 in plasma cells reactive to TG2, a primary celiac antigen (72). The researchers quantified the percentage of IGHV5-51 antibodies in anti-TG2 IgA repertoires of patients in various stages of disease and observed that IGHV5-51 percentage was well correlated with disease severity, suggesting a pathogenic role for these antibodies. Looking forward, proteomic study of the 'autoantibody repertoire' with Ig-Seq may help us understand this repertoire's behavior before symptom onset, a crucial step in the reversal or treatment of autoimmunity (70, 72-74).

In some cases, trends observed in B cell populations and the secreted repertoire differ, highlighting the utility of direct proteomic analysis in characterizing the mechanisms of autoimmune pathology. In an illustrative example, Stanley and colleagues followed up on an earlier study (75) investigating B cells specific to the Dsg3 autoantigen in pemphigus vulgaris patients, interrogating the anti-Dsg3 autoantibodies in serum using Ig-Seq (76). Their initial B cell sequencing work had revealed a gene preference for IGHV1-46 among the Dsg3reactive $\mathrm{B}$ cell population, but the new study demonstrated that the functional, secreted antibody repertoire did not share this preference, and was more diverse than what was observed in the B cell compartment. Moreover, longitudinal analysis over several years revealed a substantial change in the abundances of individual anti-Dsg3 antibodies in circulation over time, though a subset of the highly abundant antibodies persist for years, as well as a significant portion of antibody sequences observed by transcriptomic methods.

\section{Cancer}

Though few studies have examined cancer antibody repertoire via Ig-Seq, initial studies indicate that MS-based analysis of sera can be used for increased sensitivity in monitoring malignancies. For example, a study investigating multiple myeloma (MM) patient serum antibodies (77) was able to detect MM-specific antibodies in patients that had returned false-negative results via protein electrophoresis and serum immunofixation, both standard procedures for molecular detection of myeloma (78). A separate study (79) attempted to create a screen for non-smallcell lung cancer based on serum antibody CDR's detected using mass spectrometry. This work suggests that peptide signatures have potential as tools for cancer detection (80), though other studies in humans and animal models have suggested that antigen-specific antibody repertoires do not exhibit major overlap between individuals $(76,81,82)$. Separately, interrogating the tumor immune repertoire has resulted in the identification of tumor-specific antibodies, which can be developed as therapeutics or used to discover novel binding targets (83). McDaniel et al. (84) analyzed serum antibodies from breast cancer patients who had tested positive for the cancer testis antigen NY-ESO-1, a marker normally confined to male germ cells but present in up to $25 \%$ of breast cancers. Serum antibodies identified from Ig-Seq and expressed as mAbs bound to NY-ESO-1 with $\mathrm{K}_{\mathrm{D}}$ as low as $2.0 \mathrm{nM}$.

\section{ALTERNATIVE METHODS FOR IMMUNOPROTEOMIC ANALYSIS OF DISEASE}

Ig-Seq is a bottom-up proteomic method involving injection of proteolytically-digested peptides into the LC-MS system (85); trypsin is a good choice for Ig-Seq studies due to the prevalence of arginine or lysine residues flanking the antibody CDR-H3 region. However, proteolytic digestion with trypsin or any other proteases may lead to loss of detectable CDR-H3 peptides and reduce the quantity of identifiable CDR-H3 sequences. To address this, other groups have used top-down 
or middle-down proteomic approaches, which preserve sequence coverage at the expense of resolution; nevertheless, these methods have resulted in useful insight regarding the antibody repertoire [reviewed in (26)]. Bottom-up approaches have also sought to increase coverage by digesting samples with complementary proteases and using computational pipelines to construct intact antibody sequences (86). Separately, Ig-Seq relies on reference antibody databases to deconvolute peptide spectra; the quality, size and source of the database can significantly impact the results and accuracy of antibody identification (26). Several groups are attempting to overcome this dependence using germline gene sequence databases available through online resources, such as IMGT $(72,87,88)$. However, database matching cannot discern exact sequences of antibodies, as their CDR-H3's specifically are formed only after somatic hypermutation in their secreting B cells. Reference-free sequencing of antigen-specific immunoglobulins from biological fluids via mass spectrometry would address this limitation, though this remains difficult due to the complexity and high variability of antibody variable regions. Recent methods have enabled sequencing of full-length purified mAbs at close to $100 \%$ accuracy (89), implementing error correction with database homology searches and introducing mutations and posttranslational modifications to converge on exact sequences. Some groups have combined similar pipelines with database matching and have been successful in sequencing antibodies from highly restricted populations, as in autoimmune disease (90). More recent work suggests that antibodies will soon be sequenced directly from repertoires with enough precision to allow recombinant expression $(82,91)$.

\section{DISCUSSION}

Numerous studies have utilized Ig-Seq to identify individual antibodies in serum and track how their abundances change over time in the contexts of various pathologies $(34,39,42,54$, $55,57,66,76)$. This is of particular interest in viral diseases, as there is increasing evidence that exposure history plays a decisive role in the antibody response to infection or vaccination $(39,54$, 92, 93). Though the effects of immune imprinting have been most extensively studied in influenza $(34,39,42)$, recent work in $\mathrm{HuNoV}$ has revealed boosting of persistent cross-reactive antibodies in response to vaccination (54). Further, emerging research in SARS-CoV-2 indicates that the antibody repertoire may be shaped by previous infection with endemic coronaviruses, suggesting that exposure history may play a critical role in other viral immune responses $(92,93)$. Tracking individual antibody abundances over longitudinal samples will allow us to measure the relative contributions to protection made by pre-existing and de novo antibodies. Describing both of these antibody populations on a disease-specific basis will be necessary for understanding the immunopathogenesis of infection and evaluating the effectiveness of vaccines.

The Ig-Seq pipeline has yielded high-affinity, broadly neutralizing antibodies reactive to SARS-CoV-2, influenza,
$\mathrm{HIV}$, and HuNoV, demonstrating the broad potential of the method in discovering novel therapeutics $(54,62,64)$. Notably, this method has allowed groups to identify immune 'signatures' of exposure, such as the presence of broadly-reactive antibodies against select influenza (34) or norovirus strains (54), or nonprotective antibodies to a conserved epitope on SARS-CoV-2 (93). These and similar data may inform the design of nextgeneration vaccines customized for an individual's exposure history. For example, a novel vaccine may present epitopes known to boost pre-existing, broadly neutralizing antibodies and avoid presenting epitopes known to be associated with previous non-protective immune responses. It is worth noting, however, that this strategy cannot predict immune escape mutations, which may occur even on conserved epitopes.

Ig-Seq holds promise as a means to profile the secreted antibody repertoire at mucosal surfaces, including the respiratory and intestinal tracts (94-98) (Figure 1). Functional characterizations of site-specific antibody repertoires in diseases occurring at mucosal surfaces are highly important for treatment of individuals with respiratory conditions, such as cystic fibrosis and lung cancer. In addition, novel vaccines are being developed to target mucous membranes (99), and quantitative profiling of the mucosal immune repertoire will be essential to understand their effectiveness and function. As the source of the antibody transcript sequence database influences the quality of Ig-Seq data, subsequent work will require generating more comprehensive donor-specific reference databases using B cells from various compartments. Alternatively, substantial advances in reference-free sequencing may soon enable identification of serum antibodies without the need for such databases.

While mass spectrometric studies of the antibody repertoire span a wide breadth of disease types, more depth of study is needed to obtain additional data for developing novel therapeutic strategies in each disease case, and to validate the protective effects of those strategies. Ig-Seq will allow us to interrogate the overall immune response in unprecedented detail and use site-specific characteristics of the antibody repertoire to design novel therapeutics and vaccine strategies.

\section{AUTHOR CONTRIBUTIONS}

SI and JL wrote and revised the manuscript. All authors contributed to the article and approved the submitted version.

\section{FUNDING}

This work was supported by the National Institutes of Health [P20GM113132] and the Cystic Fibrosis Foundation [STANTO19R0].

\section{ACKNOWLEDGMENTS}

We thank Nicholas Curtis for his help in editing this manuscript. 


\section{REFERENCES}

1. Behring E, Kitasato S. Ueber Das Zustandekommen Der DiphtherieImmunität Und Der Tetanus-Immunität Bei Thieren. Deutsche Medicinische Wochenschrift (1890) 16(49):1113-4. doi: 10.1055/s-00291207589

2. Ehrlich P. Experimentelle Untersuchungen Über Immunität. II. Ueber Abrin. Dtsch Med Wochenschr (1891) 17(44):1218-9. doi: 10.1055/s-0029-1206825

3. Landsteiner K, van der Scheer J. On Cross-Reactions of Egg Albumin Sera. J Exp Med (1940) 71:445-54. doi: 10.1084/jem.71.4.445

4. Radbruch A, Muehlinghaus G, Luger EO, Inamine A, Smith KG, Dorner T, et al. Competence and Competition: The Challenge of Becoming a Long-Lived Plasma Cell. Nat Rev Immunol (2006) 6(10):741-50. doi: 10.1038/nri1886

5. Spencer J, Sollid LM. The Human Intestinal B-Cell Response. Mucosal Immunol (2016) 9(5):1113-24. doi: 10.1038/mi.2016.59

6. Cox RJ, Brokstad KA, Zuckerman MA, Wood JM, Haaheim LR, Oxford JS. An Early Humoral Immune Response in Peripheral Blood Following Parenteral Inactivated Influenza Vaccination. Vaccine (1994) 12(11):993-9. doi: 10.1016/0264-410X(94)90334-4

7. Wrammert J, Smith K, Miller J, Langley WA, Kokko K, Larsen C, et al. Rapid Cloning of High-Affinity Human Monoclonal Antibodies Against Influenza Virus. Nature (2008) 453(7195):667-71. doi: 10.1038/nature06890

8. Hobson D, Curry RL, Beare AS, Ward-Gardner A. The Role of Serum Hemagglutination-Inhibiting Antibody in Protecting Against Challenge Infection With Influenza A2 and B Viruses. J Hygiene (1972) 70(767): 767-77. doi: $10.1017 /$ S0022172400022610

9. Miller MS, Gardner TJ, Krammer F, Aguado LC, Tortorella D, Basler CF, et al. Neutralizing Antibodies Against Previously Encountered Influenza Virus Strains Increase Over Time: A Longitudinal Analysis. Sci Trans Med (2013) 5(198):198ra107. doi: 10.1126/scitranslmed.3006637

10. Feng S, Phillips DJ, White T, Sayal H, Aley PK, Bibi S, et al. Correlates of Protection Against Symptomatic and Asymptomatic SARS-CoV-2 Infection. Nat Med (2021) 27:2032-40. doi: 10.1101/2021.06.21.21258528

11. Nelson AL, Dhimolea E, Reichert JM. Development Trends for Human Monoclonal Antibody Therapeutics. Nat Rev Drug Discovery (2010) 9 (10):767-74. doi: $10.1038 / \mathrm{nrd} 3229$

12. Plotkin SA. Correlates of Protection Induced by Vaccination. Clin Vaccine Immunol (2010) 17(7):1055-65. doi: 10.1128/CVI.00131-10

13. Aebersold R, Mann M. Mass Spectrometry-Based Proteomics. Nature (2003) 422:198-207. doi: 10.1038/nature01511

14. Wine Y, Boutz DR, Lavinder JJ, Miklos AE, Hughes RA, Hoi KH, et al. Molecular Deconvolution of the Monoclonal Antibodies That Comprise the Polyclonal Serum Response. Proc Natl Acad Sci U S A (2013) 110(8):2993-8. doi: 10.1073/pnas.1213737110

15. Lavinder JJ, Wine Y, Giesecke C, Ippolito GC, Horton AP, Lungu OI, et al. Identification and Characterization of the Constituent Human Serum Antibodies Elicited by Vaccination. Proc Natl Acad Sci U S A (2014) 111 (6):2259-64. doi: 10.1073/pnas.1317793111

16. Cheung WC, Beausoleil SA, Zhang X, Sato S, Schieferl SM, Wieler JS, et al. A Proteomics Approach for the Identification and Cloning of Monoclonal Antibodies From Serum. Nat Biotechnol (2012) 30(5):447-52. doi: 10.1038/ nbt. 2167

17. Sato S, Beausoleil SA, Popova L, Beaudet JG, Ramenani RK, Zhang X, et al. Proteomics-Directed Cloning of Circulating Antiviral Human Monoclonal Antibodies. Nat Biotechnol (2012) 30(11):1039-43. doi: 10.1038/nbt.2406

18. Wine Y, Horton AP, Ippolito GC, Georgiou G. Serology in the 21st Century: The Molecular-Level Analysis of the Serum Antibody Repertoire. Curr Opin Immunol (2015) 35:89-97. doi: 10.1016/j.coi.2015.06.009

19. Nesvizhskii AI. Proteogenomics: Concepts, Applications and Computational Strategies. Nat Methods (2014) 11(11):1114-25. doi: 10.1038/nmeth.3144

20. Curtis NC, Lee J. Beyond Bulk Single-Chain Sequencing: Getting at the Whole Receptor. Curr Opin Syst Biol (2020) 24:93-9. doi: 10.1016/j.coisb.2020.10.008

21. Friedensohn S, Khan TA, Reddy ST. Advanced Methodologies in HighThroughput Sequencing of Immune Repertoires. Trends Biotechnol (2017) 35(3):203-14. doi: 10.1016/j.tibtech.2016.09.010

22. Robinson WH. Sequencing the Functional Antibody Repertoire - Diagnostic and Therapeutic Discovery. Nat Rev Rheumatol (2015) 11:171-82. doi: 10.1038/nrrheum.2014.220
23. DeKosky BJ, Kojima T, Rodin A, Charab W, Ippolito GC, Ellington AD, et al. In Depth Determination and Analysis of the Human Paired Heavy- and LightChain Antibody Repertoire. Nat Med (2015) 21(1):86-91. doi: 10.1038/nm.3743

24. McDaniel JR, DeKosky BJ, Tanno H, Ellington AD, Georgiou G. Ultra-HighThroughput Sequencing of the Immune Receptor Repertoire From Millions of Lymphocytes. Nat Protoc (2016) 11(3):429-42. doi: 10.1038/nprot.2016.024

25. Mason DM, Friedensohn S, Weber CR, Jordi C, Wagner B, Meng SM, et al. Optimization of Therapeutic Antibodies by Predicting Antigen Specificity From Antibody Sequence via Deep Learning. Nat Biomed Eng (2021) 5 (6):600-12. doi: 10.1038/s41551-021-00699-9

26. Snapkov I, Chernigovskaya M, Sinitcyn P, Le Quy K, Nyman TA, Greiff V. Progress and Challenges in Mass Spectrometry-Based Analysis of Antibody Repertoires. Trends Biotechnol (2021). doi: 10.1016/j.tibtech.2021.08.006

27. Francis T, Salk KE, Quilligan JJ. Experience With Vaccination Against Influenza in the Spring of 1947: A Preliminary Report. Am J Public Health Nations Health (1947) 37:1013-6. doi: 10.2105/AJPH.37.8.1013

28. Francis T. On the Doctrine of Original Antigenic Sin. Proc Am Philos Soc (1960) 104(6):572-8. Available at: https://www.jstor.org/stable/985534.

29. Fonville JM, Wilks S, James SL, Fox A, Ventresca M, Aban M, et al. Antibody Landscapes After Influenza Virus Infection or Vaccination. Science (2014) 346 (6212):996-1000. doi: 10.1126/science.1256427

30. Gostic KM, Ambrose M, Worobey M, Lloyd-Smith JO. Potent Protection Against H5N1 and H7N9 Influenza via Childhood Hemagglutinin Imprinting. Science (2016) 354(6313):722-6. doi: 10.1126/science.aag1322

31. Krammer F. The Human Antibody Response to Influenza a Virus Infection and Vaccination. Nat Rev Immunol (2019) 19(6):383-97. doi: 10.1038/s41577019-0143-6

32. Dugan HL, Guthmiller JJ, Arevalo P, Huang M, Chen Y, Neu K, et al. Preexisting Immunity Shapes Distinct Antibody Landscapes After Influenza Virus Infection and Vaccination in Humans. Sci Trans Med (2020) 12: eabd3601. doi: 10.1126/scitranslmed.abd3601

33. McCarthy KR, Von Holle TA, Sutherland LL, Oguin TH, Sempowski GD, Harrison SC, et al. Differential Immune Imprinting by Influenza Virus Vaccination and Infection in Nonhuman Primates. Proc Natl Acad Sci U S A (2021) 118(23):e2026752118. doi: 10.1073/pnas.2026752118

34. Lee J, Boutz DR, Chromikova V, Joyce MG, Vollmers C, Leung K, et al. Molecular-Level Analysis of the Serum Antibody Repertoire in Young Adults Before and After Seasonal Influenza Vaccination. Nat Med (2016) 22 (12):1456-64. doi: 10.1038/nm.4224

35. Watanabe A, McCarthy KR, Kuraoka M, Schmidt AG, Adachi Y, Onodera T, et al. Antibodies to a Conserved Influenza Head Interface Epitope Protect by an Igg Subtype-Dependent Mechanism. Cell (2019) 177(5):1124-35.e16. doi: 10.1016/j.cell.2019.03.048

36. Bangaru S, Lang S, Schotsaert M, Vanderven HA, Zhu X, Kose N, et al. A Site of Vulnerability on the Influenza Virus Hemagglutinin Head Domain Trimer Interface. Cell (2019) 177(5):1136-52.e18. doi: 10.1016/j.cell.2019.04.011

37. Bajic G, Maron MJ, Adachi Y, Onodera T, McCarthy KR, McGee CE, et al. Influenza Antigen Engineering Focuses Immune Responses to a Subdominant But Broadly Protective Viral Epitope. Cell Host Microbe (2019) 25(6):82735.e6. doi: 10.1016/j.chom.2019.04.003

38. McCarthy KR, Lee J, Watanabe A, Kuraoka M, Robinson-McCarthy LR, Georgiou G, et al. A Prevalent Focused Human Antibody Response to the Influenza Virus Hemagglutinin Head Interface. mBio (2021) 12(3):e0114421. doi: $10.1128 / \mathrm{mBio} .01144-21$

39. Lee J, Paparoditis P, Horton AP, Fruhwirth A, McDaniel JR, Jung J, et al. Persistent Antibody Clonotypes Dominate the Serum Response to Influenza Over Multiple Years and Repeated Vaccinations. Cell Host Microbe (2019) 25 (3):367-76.e5. doi: 10.1016/j.chom.2019.01.010

40. Bodewes R, de Mutsert G, van der Klis FR, Ventresca M, Wilks S, Smith DJ, et al. Prevalence of Antibodies Against Seasonal Influenza a and B Viruses in Children in Netherlands. Clin Vaccine Immunol (2011) 18(3):469-76. doi: 10.1128/CVI.00396-10

41. Frasca D, Diaz A, Romero M, Landin AM, Phillips M, Lechner SC, et al. Intrinsic Defects in B Cell Response to Seasonal Influenza Vaccination in Elderly Humans. Vaccine (2010) 28(51):8077-84. doi: 10.1016/ j.vaccine.2010.10.023

42. Jung J, Mundle ST, Ustyugova IV, Horton AP, Boutz DR, Pougatcheva S, et al. Influenza Vaccination in the Elderly Boosts Antibodies Against Conserved 
Viral Proteins and Egg-Produced Glycans. J Clin Invest (2021) 131(13): e148763. doi: 10.1172/JCI148763

43. Wagner A, Guzek A, Ruff J, Jasinska J, Scheikl U, Zwazl I, et al. Neutralising SARS-CoV-2 RBD-Specific Antibodies Persist for at Least Six Months Independently of Symptoms in Adults. Commun Med (2021) 1(1):13. doi: 10.1038/s43856-021-00012-4

44. Seow J, Graham C, Merrick B, Acors S, Pickering S, Steel KJA, et al. Longitudinal Observation and Decline of Neutralizing Antibody Responses in the Three Months Following SARS-CoV-2 Infection in Humans. Nat Microbiol (2020) 5(12):1598-607. doi: 10.1038/s41564-020-00813-8

45. Algaissi A, Alfaleh MA, Hala S, Abujamel TS, Alamri SS, Almahboub SA, et al. SARS-CoV-2 S1 and N-Based Serological Assays Reveal Rapid Seroconversion and Induction of Specific Antibody Response in COVID-19 Patients. Sci Rep (2020) 10(1):16561. doi: 10.1038/s41598-020-73491-5

46. Butler SE, Crowley AR, Natarajan H, Xu S, Weiner JA, Bobak CA, et al. Distinct Features and Functions of Systemic and Mucosal Humoral Immunity Among SARS-CoV-2 Convalescent Individuals. Front Immunol (2020) 11:618685. doi: 10.3389/fimmu.2020.618685

47. Wrapp DW, Wang N, Corbett KS, Goldsmith JA, Hsieh C-L, Abiona O, et al. Cryo-EM Structure of the 2019-NCoV Spike in the Prefusion Conformation. Science (2020) 367:1260-3. doi: 10.1126/science.abb2507

48. Robbiani DF, Gaebler C, Muecksch F, Lorenzi JCC, Wang Z, Cho A, et al. Convergent Antibody Responses to SARS-CoV-2 in Convalescent Individuals. Nature (2020) 584(7821):437-42. doi: 10.1038/s41586-020-2456-9

49. ter Meulen J, van den Brink EN, Poon LL, Marissen WE, Leung CS, Cox F, et al. Human Monoclonal Antibody Combination Against SARS Coronavirus: Synergy and Coverage of Escape Mutants. PLoS Med (2006) 3(7):e237. doi: 10.1371/journal.pmed.0030237

50. Liu L, Wang P, Nair MS, Yu J, Rapp M, Wang Q, et al. Potent Neutralizing Antibodies Against Multiple Epitopes on SARS-CoV-2 Spike. Nature (2020) 584(7821):450-6. doi: 10.1038/s41586-020-2571-7

51. Rappazzo CG, Tse LV, Kaku CI, Wrapp DW, Sakharkar M, Huang D, et al. Broad and Potent Activity Against SARS-Like Virusesby an Engineered Human Monoclonal Antibody. Science (2021) 371:823-39. doi: 10.1126/ science.abf 4830

52. Wec AZ, Wrapp DW, Herbert AS, Maurer DP, Haslwanter D, Sakharkar M, et al. Broad Neutralization of SARS-Related Viruses by Human Monoclonal Antibodies. Science (2020) 369:731-6. doi: 10.1126/science.abc7424

53. Kim SI, Noh J, Kim S, Choi Y, Yoo DK, Lee Y, et al. Stereotypic Neutralizing VH Antibodies Against SARS-CoV-2 Spike Protein Receptor Binding Domain in Patients With COVID-19 and Healthy Individuals. Sci Trans Med (2021) 13:eabd6990. doi: 10.1126/scitranslmed.abd6990

54. Lindesmith LC, McDaniel JR, Changela A, Verardi R, Kerr SA, Costantini V, et al. Sera Antibody Repertoire Analyses Reveal Mechanisms of Broad and Pandemic Strain Neutralizing Responses After Human Norovirus Vaccination. Immunity (2019) 50(6):1530-41.e8. doi: 10.1016/ j.immuni.2019.05.007

55. Voss WN, Hou YJ, Johnson NV, Delidakis G, Eyun Kim J, Javanmardi K, et al. Prevalent, Protective, and Convergent Igg Recognition of SARS-CoV-2 NonRBD Spike Epitopes. Science (2021) 372:1106-12. doi: 10.1126/ science.abg5268

56. Walensky RP, Walke HT, Fauci AS. SARS-CoV-2 Variants of Concern in the United States-Challenges and Opportunities. JAMA (2021) 325(11):1037-8. doi: 10.1001/jama.2021.2294

57. Wheatley AK, Juno JA, Wang JJ, Selva KJ, Reynaldi A, Tan HX, et al. Evolution of Immune Responses to SARS-CoV-2 in Mild-Moderate COVID-19. Nat Commun (2021) 12(1):1162. doi: 10.1038/s41467-021-21444-5

58. Kitteringham NR, Jenkins RE, Lane CS, Elliott VL, Park BK. Multiple Reaction Monitoring for Quantitative Biomarker Analysis in Proteomics and Metabolomics. J Chromatogr B Analyt Technol BioMed Life Sci (2009) 877 (13):1229-39. doi: 10.1016/j.jchromb.2008.11.013

59. Hansen CH, Michlmayer D, Gubbels SM, Molbak K, Ethelberg S. Assessment of Protection Against Reinfection With SARS-CoV-2 Among 4 Million PCRTested Individuals in Denmark in 2020: A Population-Level Observational Study. Lancet (2021) 397:1204-12. doi: 10.1016/S0140-6736(21)00575-4

60. Iacob SA, Iacob DG. Ibalizumab Targeting CD4 Receptors, an Emerging Molecule in HIV Therapy. Front Microbiol (2017) 8:2323. doi: 10.3389/ fmicb.2017.02323
61. Bonsignori M, Liao HX, Gao F, Williams WB, Alam SM, Montefiori DC, et al. Antibody-Virus Co-Evolution in HIV Infection: Paths for HIV Vaccine Development. Immunol Rev (2017) 275(1):145-60. doi: 10.1111/imr.12509

62. Williams LD, Ofek G, Schatzle S, McDaniel JR, Lu X, Nicely NI, et al. Potent and Broad HIV-Neutralizing Antibodies in Memory B Cells and Plasma. Sci Immunol (2017) 2(7):eaal2200. doi: 10.1126/sciimmunol.aal2200

63. Simek MD, Rida W, Priddy FH, Pung P, Carrow E, Laufer DS, et al. Human Immunodeficiency Virus Type 1 Elite Neutralizers: Individuals With Broad and Potent Neutralizing Activity Identified by Using a High-Throughput Neutralization Assay Together With an Analytical Selection Algorithm. J Virol (2009) 83(14):7337-48. doi: 10.1128/JVI.00110-09

64. Sajadi MM, Dashti A, Rikhtegaran Tehrani Z, Tolbert WD, Seaman MS, Ouyang X, et al. Identification of Near-Pan-Neutralizing Antibodies Against HIV-1 by Deconvolution of Plasma Humoral Responses. Cell (2018) 173 (7):1783-95.e14. doi: 10.1016/j.cell.2018.03.061

65. Coelho CH, Nadakal ST, Gonzales Hurtado P, Morrison R, Galson JD, Neal J, et al. Antimalarial Antibody Repertoire Defined by Plasma IG Proteomics and Single B Cell IG Sequencing. JCI Insight (2020) 5(22):29532. doi: 10.1172/ jci.insight.143471

66. Ogishi M, Yotsuyanagi H, Moriya K, Koike K. Delineation of Autoantibody Repertoire Through Differential Proteogenomics in Hepatitis C VirusInduced Cryoglobulinemia. Sci Rep (2016) 6:29532. doi: 10.1038/srep29532

67. Tipton CM, Hom JR, Fucile CF, Rosenberg AF, Sanz I. Understanding B-Cell Activation and Autoantibody Repertoire Selection in Systemic Lupus Erythematosus: A B-Cell Immunomics Approach. Immunol Rev (2018) 284 (1):120-31. doi: 10.1111/imr.12660

68. Villar LM, Sadaba MC, Roldan E, Masjuan J, Gonzalez-Porque P, Villarrubia $\mathrm{N}$, et al. Intrathecal Synthesis of Oligoclonal Igm Against Myelin Lipids Predicts an Aggressive Disease Course in MS. J Clin Invest (2005) 115(1):18794. doi: $10.1172 /$ JCI22833

69. Hammers CM, Stanley JR. Mechanisms of Disease: Pemphigus and Bullous Pemphigoid. Аnnu Rev Pathol: Mech Dis (2016) 11:175-97. doi: 10.1146/ annurev-pathol-012615-044313

70. Tipton CM, Fucile CF, Darce J, Chida A, Ichikawa T, Gregoretti I, et al. Diversity, Cellular Origin and Autoreactivity of Antibody-Secreting Cell Population Expansions in Acute Systemic Lupus Erythematosus. Nat Immunol (2015) 16(7):755-65. doi: 10.1038/ni.3175

71. Wang JJ, Colella AD, Beroukas D, Chataway TK, Gordon TP. Precipitating Anti-Dsdna Peptide Repertoires in Lupus. Clin Exp Immunol (2018) 194 (3):273-82. doi: 10.1111/cei.13197

72. Iversen R, Roy B, Stamnaes J, Hoydahl LS, Hnida K, Neumann RS, et al. Efficient T Cell-B Cell Collaboration Guides Autoantibody Epitope Bias and Onset of Celiac Disease. Proc Natl Acad Sci U S A (2019) 116(30):15134-9. doi: 10.1073/pnas.1901561116

73. Singh M, Jackson KJL, Wang JJ, Schofield P, Field MA, Koppstein D, et al. Lymphoma Driver Mutations in the Pathogenic Evolution of an Iconic Human Autoantibody. Cell (2020) 180(5):878-94.e19. doi: 10.1016/j.cell.2020.01.029

74. Obermeier B, Mentele R, Malotka J, Kellermann J, Kumpfel T, Wekerle H, et al. Matching of Oligoclonal Immunoglobulin Transcriptomes and Proteomes of Cerebrospinal Fluid in Multiple Sclerosis. Nat Med (2008) 14 (6):688-93. doi: 10.1038/nm1714

75. Cho MJ, Lo AS, Mao X, Nagler AR, Ellebrecht CT, Mukherjee EM, et al. Shared VH1-46 Gene Usage by Pemphigus Vulgaris Autoantibodies Indicates Common Humoral Immune Responses Among Patients. Nat Commun (2014) 5:4167. doi: 10.1038/ncomms5167

76. Chen J, Zheng Q, Hammers CM, Ellebrecht CT, Mukherjee EM, Tang HY, et al. Proteomic Analysis of Pemphigus Autoantibodies Indicates a Larger, More Diverse, and More Dynamic Repertoire Than Determined by B Cell Genetics. Cell Rep (2017) 18(1):237-47. doi: 10.1016/j.celrep.2016.12.013

77. Barnidge DR, Tschumper RC, Theis JD, Snyder MR, Jelinek DF, Katzmann JA, et al. Monitoring M-Proteins in Patients With Multiple Myeloma Using Heavy-Chain Variable Region Clonotypic Peptides and LC-MS/MS. J Proteome Res (2014) 13(4):1905-10. doi: 10.1021/pr5000544

78. Rajkumar SV. Multiple Myeloma: 2016 Update on Diagnosis, RiskStratification, and Management. Am J Hematol (2016) 91(7):719-34. doi: 10.1002/ajh.24402

79. de Costa D, Broodman I, Calame W, Stingl C, Dekker LJ, Vernhout RM, et al. Peptides From the Variable Region of Specific Antibodies are Shared Among 
Lung Cancer Patients. PLoS One (2014) 9(5):e96029. doi: 10.1371/ journal.pone. 0096029

80. Broodman I, Lindemans J, van Sten J, Bischoff R, Luider T. Serum Protein Markers for the Early Detection of Lung Cancer: A Focus on Autoantibodies. J Proteome Res (2017) 16(1):3-13. doi: 10.1021/acs.jproteome.6b00559

81. VanDuijn MM, Dekker LJ, van IWFJ, Sillevis Smitt PAE, Luider TM. Immune Repertoire After Immunization as Seen by Next-Generation Sequencing and Proteomics. Front Immunol (2017) 8:1286. doi: 10.3389/fimmu.2017.01286

82. Bondt A, Hoek M, Tamara S, de Graaf B, Peng W, Schulte D, et al. Human Plasma Igg1 Repertoires Are Simple, Unique, and Dynamic. Cell Syst (2021) 12:1131-43. doi: 10.2139/ssrn.3749694

83. Haen SP, Loffler MW, Rammensee HG, Brossart P. Towards New Horizons: Characterization, Classification and Implications of the Tumour Antigenic Repertoire. Nat Rev Clin Oncol (2020) 17(10):595-610. doi: 10.1038/s41571020-0387-x

84. McDaniel JR, Pero SC, Voss WN, Shukla GS, Sun Y, Schaetzle S, et al. Identification of Tumor-Reactive B Cells and Systemic Igg in Breast Cancer Based on Clonal Frequency in the Sentinel Lymph Node. Cancer Immunol Immunother (2018) 67(5):729-38. doi: 10.1007/s00262-018-2123-2

85. Gillet LC, Leitner A, Aebersold R. Mass Spectrometry Applied to Bottom-Up Proteomics: Entering the High-Throughput Era for Hypothesis Testing. Annu Rev Analytical Chem (2016) 9:449-72. doi: 10.1146/annurev-anchem-071015041535

86. Peng W, Pronker MF, Snijder J. Mass Spectrometry-Based De Novo Sequencing of Monoclonal Antibodies Using Multiple Proteases and a Dual Fragmentation Scheme. J Proteome Res (2021) 20(7):3559-66. doi: 10.1021/ acs.jproteome.1c00169

87. Zhang J, Xin L, Shan B, Chen W, Xie M, Yuen D, et al. PEAKS DB: De Novo Sequencing Assisted Database Search for Sensitive and Accurate Peptide Identification. Mol Cell Proteomics (2012) 11(4):M111 010587. doi: 10.1074/ mcp.M111.010587

88. Brochet X, Lefranc MP, Giudicelli V. IMGT/V-QUEST: The Highly Customized and Integrated System for IG and TR Standardized V-J and VD-J Sequence Analysis. Nucleic Acids Res (2008) 36(Web Server issue):W5038. doi: $10.1093 / \mathrm{nar} / \mathrm{gkn} 316$

89. Tran NH, Rahman MZ, He L, Xin L, Shan B, Li M. Complete De Novo Assembly of Monoclonal Antibody Sequences. Sci Rep (2016) 6:31730. doi: $10.1038 /$ srep31730

90. Lindop R, Arentz G, Chataway TK, Thurgood LA, Jackson MW, Reed JH, et al. Molecular Signature of a Public Clonotypic Autoantibody in Primary Sjogren's Syndrome: A "Forbidden" Clone in Systemic Autoimmunity. Arthritis Rheum (2011) 63(11):3477-86. doi: 10.1002/art.30566

91. Guthals A, Gan Y, Murray L, Chen Y, Stinson J, Nakamura G, et al. De Novo MS/MS Sequencing of Native Human Antibodies. J Proteome Res (2017) 16 (1):45-54. doi: 10.1021/acs.jproteome.6b00608
92. Morgenlander WR, Henson SN, Monaco DR, Chen A, Littlefield K, Bloch EM, et al. Antibody Responses to Endemic Coronaviruses Modulate COVID-19 Convalescent Plasma Functionality. J Clin Invest (2021) 131(7):e146927. doi: $10.1172 / J C I 146927$

93. Crowley AR, Natarajan H, Hederman AP, Bobak CA, Weiner JA, WielandAlter W, et al. Boosting of Cross-Reactive Antibodies to Endemic Coronaviruses by SARS-CoV-2 Infection But Not Vaccination With Stabilized Spike. medRxiv (2021). doi: 10.1101/2021.10.27.21265574

94. Briney BS, Willis JR, Finn JA, McKinney BA, Crowe JEJr. Tissue-Specific Expressed Antibody Variable Gene Repertoires. PLoS One (2014) 9(6): e100839. doi: 10.1371/journal.pone.0100839

95. Holmgren J, Czerkinsky C. Mucosal Immunity and Vaccines. Nat Med (2005) 11(4 Suppl):S45-53. doi: $10.1038 / \mathrm{nm} 1213$

96. Theprungsirikul J, Skopelja-Gardner S, Meagher RE, Clancy JP, Zemanick ET, Ashare A, et al. Dissociation of Systemic and Mucosal Autoimmunity in Cystic Fibrosis. J Cyst Fibros (2020) 19(2):196-202. doi: 10.1016/ j.jcf.2019.06.006

97. Yadav R, Yoo DG, Kahlenberg JM, Bridges SLJr., Oni O, Huang H, et al. Systemic Levels of Anti-PAD4 Autoantibodies Correlate With Airway Obstruction in Cystic Fibrosis. J Cyst Fibros (2019) 18(5):636-45. doi: 10.1016/j.jcf.2018.12.010

98. Mauch RM, Jensen PO, Moser C, Levy CE, Hoiby N. Mechanisms of Humoral Immune Response Against Pseudomonas Aeruginosa Biofilm Infection in Cystic Fibrosis. J Cyst Fibros (2018) 17(2):143-52. doi: 10.1016/j.jcf.2017.08.012

99. Matsuda K, Migueles SA, Huang J, Bolkhovitinov L, Stuccio S, Griesman T, et al. A Replication-Competent Adenovirus-Vectored Influenza Vaccine Induces Durable Systemic and Mucosal Immunity. J Clin Invest (2021) 131 (5):e140794. doi: 10.1172/JCI140794

Conflict of Interest: The authors declare that the research was conducted in the absence of any commercial or financial relationships that could be construed as a potential conflict of interest.

Publisher's Note: All claims expressed in this article are solely those of the authors and do not necessarily represent those of their affiliated organizations, or those of the publisher, the editors and the reviewers. Any product that may be evaluated in this article, or claim that may be made by its manufacturer, is not guaranteed or endorsed by the publisher.

Copyright (C) 2022 Ionov and Lee. This is an open-access article distributed under the terms of the Creative Commons Attribution License (CC BY). The use, distribution or reproduction in other forums is permitted, provided the original author(s) and the copyright owner(s) are credited and that the original publication in this journal is cited, in accordance with accepted academic practice. No use, distribution or reproduction is permitted which does not comply with these terms. 